\title{
Prescription of oxygen concentrators for long term oxygen treatment: reassessment in one district
}

\author{
Martin J Walshaw, Richard Lim, Christopher C Evans, Charles R K Hind
}

\begin{abstract}
When oxygen concentrators became available on form FP10 in 1985 the Department of Health and Social Security issued clear guidelines for their prescription for long term treatment. Reassessment of those patients prescribed a concentrator in one district showed that 29 out of 61 patients did not fulfil these criteria. Furthermore, in only 28 cases was the daily use of the machine appropriate, though this did not reflect poor patient cooperation but was a result of inadequate prescribing instructions. In addition, 12 out of 54 patients continued to smoke. Overall, in only 18 of the 61 cases was both the prescription appropriate and the concentrator properly used.

These results suggest a need for better cooperation between general practitioner and hospital in the initial assessment of patients for long term oxygen treatment and better education of both doctor and patient in the use of oxygen concentrators.
\end{abstract}

\section{Introduction}

The oxygen concentrator is the most convenient and cost effective method of giving long term domiciliary oxygen-defined as continuous treatment with oxygen for 15 hours or more a day over a long period. ${ }^{1}$ Since December 1985 it has been possible for general practitioners in England and Wales to prescribe this machine on form FP10. ${ }^{2}$ The Department of Health and Social Security issued clear guidelines on which categories of patients might benefit from and therefore be suitable for this treatment (see appendix), ${ }^{2}$ based on the results of clinical trials. ${ }^{34}$ The guidelines also emphasised the importance of regular follow up in respiratory outpatient clinics and that patients who continued to smoke were unlikely to gain much benefit. ${ }^{2}$

To heed the DHSS guidelines several minimum requirements need to be met. Firstly, patients should be evaluated within a hospital setting to select those suitable for treatment. Secondly, the cooperation of the patient is required both to use the oxygen concentrator for at least 15 hours a day and to stop smoking. As chest physicians we gained the impression that these minimum requirements were not being met in the Liverpool district, a view shared by the local family practitioner committee. With the aid of the committee, therefore, patients who had been prescribed an oxygen concentrator in the first 22 months of their availability on form FP10 were reviewed. Our aims were, firstly, to see how many of these patients fulfilled the DHSS criteria for the prescription of long term oxygen treatment and, secondly, to see how many were using their concentrators properly.

\section{Patients and methods}

A list of the 91 patients in the Liverpool district who had been prescribed oxygen concentrators on form
FP10 between 1 December 1985 and 31 August 1987 was obtained from the family practitioner committee. Twenty of these patients had died and a further six had had their concentrators removed by the family practitioner committee for underuse (less than eight hours a day). The remaining 65 patients were invited to attend the pulmonary function laboratory at the Royal Liverpool Hospital for reassessment. Of these, 52 patients attended, eight others who were too disabled to travel being reassessed at home; one further patient with end stage fibrosing alveolitis was resident in a local hospital and was reassessed there. The remaining four patients were unavailable for reassessment; three refused to participate and one was in an unstable respiratory state in hospital.

Respiratory questionnaire - Each patient completed a respiratory questionnaire which also included details of diagnosis, past and current smoking habits, the doctor who had recommended prescription of the concentrator (general practitioner, respiratory physician, or general physician), method of delivering oxygen (nasal prongs or facemask), average use per 24 hours, and whether the patient was being followed up in a hospital clinic for the respiratory condition. (A copy of the questionnaire is available from CRKH.)

Arterial blood gas measurements-All patients were studied while in a stable clinical condition. After giving informed consent patients had their arterial blood gas tensions measured by puncture of a radial artery after breathing room air for at least one hour. In all cases blood samples were packed in ice and analysed within 30 minutes in the routine laboratory. ${ }^{5}$

Spirometry-Forced expiratory volume in one second $\left(\mathrm{FEV}_{1}\right)$ and forced vital capacity $(\mathrm{FVC})$ were measured with the same Vitalograph dry spirometer in all cases (at ambient temperature and pressure, saturated).

Prescribed and actual use of concentrator-For each patient the family practitioner committee provided details of the prescribed duration of oxygen daily - that is, number of hours' use $/ 24 \mathrm{~h}$-together with the average daily meter readings for each concentrator.

Statistical analysis-Significance of differences among groups was evaluated by Student's $t$ test.

\section{Results}

The 61 patients ( 34 men, 27 women; mean age $65 \cdot 1$ (SD 9.5) years, range 38-84) were assessed between October 1987 and January 1988. The principal diagnoses were chronic obstructive airways disease ( 55 patients), bronchiectasis (two), asbestosis (one), fibrosing alveolitis (one), and hypoventilation secondary to chest wall deformities (one case of kyphoscoliosis, one of previous thoracoplasty for pulmonary tuberculosis). Fifty four of the 61 patients had smoked before oxygen treatment (mean 52.6 pack years (SD $44 \cdot 7$ ), range $1 \cdot 5-250$ ). The patients had had their 
concentrators for an average of 12 months at the time of assessment (SD 6.4 months; range 4-22).

SOURCE OF PRESCRIPTION AND PRESCRIBED DAILY USAGE

In 17 patients the concentrator had been prescribed by the general practitioner without advice from a hospital physician (group 1), in 34 on the advice of a respiratory physician (group 2), and in 10 on the advice of a general (non-respiratory) physician (group 3).

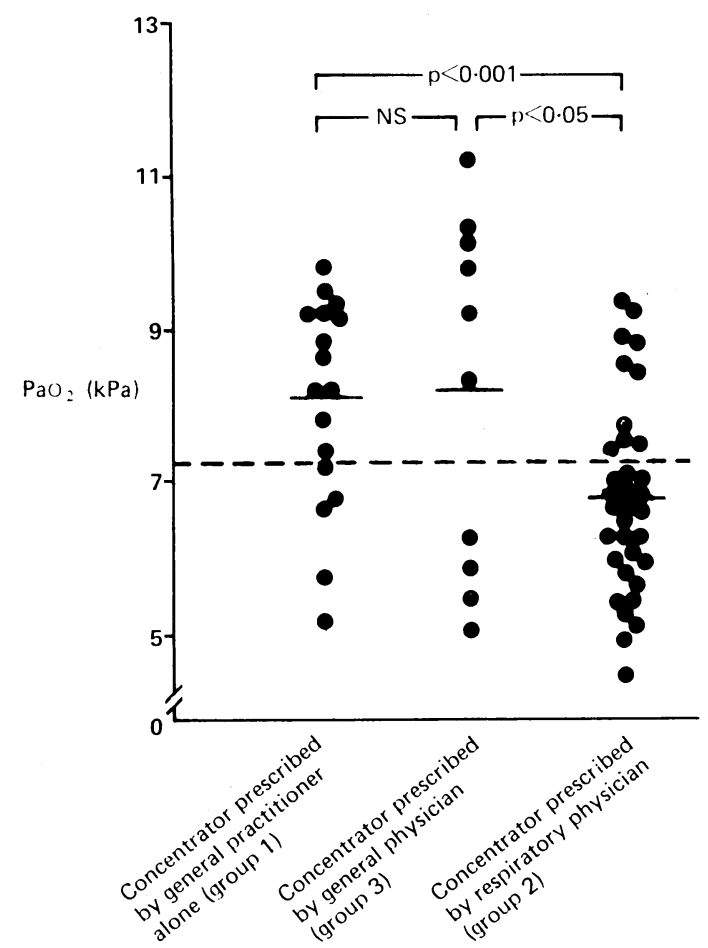

$\mathrm{PaO}_{2}$ on breathing air in patients prescribed oxygen concentrator by general practitioner without advice of hospital physician (group l), patients prescribed concentrators on advice of respiratory physician (group 2), and patients prescribed concentrator by general physician (group 3). Interrupted line indicates value $(7 \cdot 3 \mathrm{kPa})$ above which DHSS does not recommend prescribing long term oxygen treatment. Bars are means

The mean prescribed numbers of hours' use of the concentrator/24 h were: group $1,10 \cdot 5(\mathrm{SD} 2 \cdot 7$; range $8-15$ ); group $2,14 \cdot 1$ (SD $4 \cdot 0$; range $8-24$ ); group 3 , $15 \cdot 2$ (SD $5 \cdot 1$; range $10-24$ ). Only three of the 17 patients in group 1 had been prescribed 15 or more hours of oxygen daily as compared with 22 of the 34 patients in group 2 and five of the 10 in group 3. Patients in groups 2 and 3 had been prescribed significantly greater usage of oxygen than those in group $1(\mathrm{p}<0.005)$, but there was no significant difference in prescribed usage between groups 2 and 3 .

\section{ARTERIAL BLOOD GAS VALUES ON BREATHING AIR}

Patients prescribed the concentrator by a respiratory physician (group 2) had a significantly lower arterial oxygen pressure $\left(\mathrm{PaO}_{2}\right)$ on breathing air (mean 6.9 (SD $1 \cdot 2$ ) $\mathrm{kPa}$, range $4 \cdot 6-9 \cdot 4)$ than either those with machines prescribed by general physicians (group 3: mean $8 \cdot 2(2 \cdot 3) \mathrm{kPa}$, range $5 \cdot 1-11 \cdot 3)(\mathrm{p}<0 \cdot 025)$ or those whose machines were prescribed by the general practitioner alone (group 1: mean $8 \cdot 1(1 \cdot 4) \mathrm{kPa}$, range 5.3$9.8)(\mathrm{p}<0.005)$ (see figure). There was no significant difference between groups 1 and 3 . Overall only 33 of all 61 patients in the series had a $\mathrm{PaO}_{2}$ on breathing air of below $7 \cdot 3 \mathrm{kPa}$ (the cut off point recommended in the DHSS guidelines (see appendix)); these were five of the 17 patients in group 1 , four of the 10 in group 3 , and 24 of the 34 in group 2.

Similarly, patients in group 2 had a significantly higher arterial carbon dioxide tension $\left(\mathrm{PaCO}_{2}\right)$ on breathing air (mean $6.6($ SD $1 \cdot 0) \mathrm{kPa}$, range $4 \cdot 3-8 \cdot 4)$ than either group 3 (mean $5 \cdot 7(1 \cdot 3) \mathrm{kPa}$, range 4.5-8.7) $(\mathrm{p}<0.05)$ or group 1 (mean $5 \cdot 4(1 \cdot 3) \mathrm{kPa}$, range $4 \cdot 0$ $7 \cdot 0)(\mathrm{p}<0.001)$. There was no significant difference between groups 1 and 3 . Overall only 30 patients had a $\mathrm{PaCO}_{2}$ on breathing air of above $6.0 \mathrm{kPa}(4 / 17$ in group $1,2 / 10$ in group $3,24 / 34$ in group 2).

\section{SPIROMETRY}

Only one patient (group 3) had an $\mathrm{FEV}_{1}>1.51$ and an FVC $>2.01$. The remaining 60 patients had a mean $\mathrm{FEV}_{1}$ of 0.61 (SD 0.3 ; range $\left.0.3-1 \cdot 0\right)$ and a mean FVC of $1 \cdot 31$ (SD $0 \cdot 5$; range $0 \cdot 6-2 \cdot 8$ ). Patients in group 2 had a significantly lower $\mathrm{FEV}_{1}$ (mean $0.5(\mathrm{SD} 0.2)$ l, range $0.3-0.9$ ) than those in group 3 (mean $0.8(0.5) 1$, range $0 \cdot 5-2 \cdot 0)(\mathrm{p}<0.005)$ but there was no significant difference when compared with group 1 (mean $0.6(0.2) 1$, range $0 \cdot 4-1 \cdot 0)$; there was no significant difference between group 3 and group 1 . Patients in group 2 also had a significantly lower FVC (mean $1 \cdot 2$ (SD 0.4 ) 1 , range $0 \cdot 4-1.9)$ than those in group 1 (mean $1.5(0.6) 1$, range $0.6-2.8)(\mathrm{p}<0.05)$ but not those in group 3 (mean $1 \cdot 48(0 \cdot 6) 1$, range $1 \cdot 0-3 \cdot 0)$. There was no significant difference between groups 1 and 3 .

\section{PATIENT COMPLIANCE}

Use of oxygen-Comparison between the prescribed number of hours of oxygen daily with actual usage as determined from the meter readings showed no significant difference (mean prescribed duration of oxygen $13.3(\mathrm{SD} 4 \cdot 2) \mathrm{h} / 24 \mathrm{~h}$, range $8-24$; mean meter reading $14 \cdot 7(5 \cdot 3) \mathrm{h} / 24 \mathrm{~h}$, range $2-24)$. Only 28 patients ran their concentrators for at least 15 hours a day (6/17 in group $1,1 / 10$ in group 3, 21/34 in group 2). Four patients ran their concentrators for an average of less than eight hours in every 24 , and in these cases the family practitioner committee informed the general practitioner of underuse. When questioned, however, the 61 patients as a group significantly overestimated the amount of oxygen that they were using (mean estimate $16 \cdot 2(\operatorname{SD~} 3 \cdot 9) \mathrm{h} / 24 \mathrm{~h}$, range $8-24)$ as compared with the meter readings $(p<0 \cdot 001)$. Forty eight of all 61 patients estimated that they were using at least 15 hours of oxygen daily - namely, 10 of the 17 in group 1, eight of the 10 in group 3, and 30 of the 34 in group 2.

Smoking-Twelve of the 54 smokers continued to smoke after being prescribed the concentrator $(5 / 15$ in group 1, 6/13 in group 2, 1/8 in group 3).

\section{COMPLIANCE WITH DHSS GUIDELINES}

Only 32 of the 61 patients who were reassessed fulfilled the DHSS criteria for the prescription of long term oxygen treatment - that is, $\mathrm{PaO}_{2}<7 \cdot 3 \mathrm{kPa}$, $\mathrm{FEV}_{1}<1.51$, FVC $<2.01$ (see appendix). These comprised four of the 17 patients in group 1 , four of the 10 in group 3, and 24 of the 34 in group 2 . Seven of the 32 patients were still smoking and 13 failed to run their concentrators for an average of 15 hours or more daily. Overall only 18 of all 61 patients fulfilled the minimum DHSS criteria for prescribing long term oxygen treatment, had stopped smoking, and also appeared to be using their concentrators for the minimum recommended time. These comprised one of the 17 patients in group 1 , two of the 10 in group 3, and 15 of the 34 in group 2 . Only 11 of the 18 patients were regularly attending a respiratory outpatient department.

\section{Discussion}

This study confirms our impression that most patients prescribed an oxygen concentrator in this district (43/61 in this series) either do not fulfil the DHSS criteria for its prescription on form FP10 or fail to use the machine appropriately.

Over a quarter of the patients studied $(n=17)$ had 
not been assessed in a hospital setting before receiving their machine despite the clear DHSS guidelines, which state: "General practitioners who identify patients who might belong to any of these groups will wish to have consultant advice on the need for [long term oxygen treatment]." A further 16 of 44 patients who apparently had been assessed in hospital were

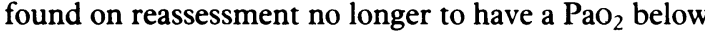
the recommended limit. Possibly some of these patients may have had an improvement in blood gas values after beginning oxygen treatment and may therefore have fulfilled the guidelines at their point of entry; such a change, however, was not noted in the original trials. ${ }^{34}$ It is also possible that a proportion of this group were originally assessed at a time when they were in an unstable respiratory condition-for example, recovering from an acute exacerbation of their chronic obstructive airways disease, in heart failure, or not receiving optimum bronchodilator treatment. The DHSS guidelines clearly state that arterial blood gas analyses should be made in a stable phase of the condition and should be repeated at an interval of not less than three weeks. Only if there is a variation of less than $0.6 \mathrm{kPa}$ in the arterial oxygen tension should long term oxygen treatment be prescribed. If this variation is exceeded then it is recommended that a further three weeks should elapse before the tests are repeated again. ${ }^{2}$

The DHSS guidelines also clearly stipulate the need for a minimum of 15 hours of treatment daily, yet in this survey 30 of the 61 patients had been prescribed less than this. Though the need for a minimum of 15 hours' treatment daily is based on clinical studies, use of a concentrator remains more economical than cylinders should a patient use it for eight hours or more a day. This may explain why the family practitioner committee informed the general practitioner of concentrator underusage only when a patient's concentrator meter reading showed that it had been running for less than eight hours a day. We accept that individual doctors do not have direct access to the concentrator meter readings and can judge oxygen usage only by the patient's own estimate. This study shows that patients tended to overestimate their oxygen consumption when compared with the meter readings, making clinical assessment of compliance with oxygen treatment difficult. We emphasise that these meter readings represent a measure of the maximum possible use of the concentrator rather than the actual amount of oxygen breathed by the patient. Despite this, patients appeared to be using similar amounts of oxygen daily to those which had originally been prescribed, suggesting that they were cooperating with this aspect of treatment. Almost a quarter of these patients, however, failed to stop smoking. These patients are thought to be unlikely to gain much benefit from long term oxygen treatment. ${ }^{26}$

This study clearly shows the need for better cooperation among general practitioners, non-respiratory physicians, and respiratory physicians in assessing the suitability of patients for long term oxygen treatment, and for a better understanding by these doctors of the clinical need for a minimum of 15 hours of oxygen daily. Apart from those patients who continued to smoke, patients appeared to cooperate with treatment provided that they were given the correct information on usage by the prescribing doctor. Compliance might be further improved if the family practitioner committee were to inform the patient's general practitioner when concentrator running time dropped below 15 hours a day.

We thank Mrs B Lea and the pulmonary function technicians of the Royal Liverpool Hospital and also Mr R Halsall of the Liverpool Family Practitioner Committee for expert help during this work.

\section{Appendix}

DHSS GUIDELINES FOR PRESCRIBING LONG TERM OXYGEN

(1) Absolute indication-Chronic obstructive airways disease with:

(a) Hypoxaemia, defined as $\mathrm{PaO}_{2}<7 \cdot 3 \mathrm{kPa}$

(b) $\mathrm{FEV}_{1}<1 \cdot 5$

(c) $\mathrm{FVC}<2.01$

(d) $\mathrm{PaCO}_{2}>6.0 \mathrm{kPa}$

(e) Oedema or previously witnessed oedema

(These tests should be made in stable phase of condition when all reversible factors have been fully treated-for example, infection, reversible airways disease, cardiac disease. In order to monitor stability, spirometric and arcerial bos me spirometric and arterial blood gas measurements should be repeated not less than three weeks later. There should be variation of not more than $20 \%$ in spirometric measurements and not more than $0.6 \mathrm{kPa}$ in arterial oxygen tension. If values have improved by more than these limits then
further three week interval should elapse and tests be repeated.)

(2) Relative indication-As in (1) but without hypercapnia or oedema.
(3) Palliative use-Other severe hypoxaemic lung disease - for example, (3) Palliative use-Other severe hypoxac
terminal phases of fibrosing alveolitis.

4) Other conditions-Palliation of chronic respiratory failure-for example, severe kyphoscoliosis, respiratory muscle disorders.

Stark RD, Finnegan P, Bishop JM. Long term domiciliary oxygen therapy in chronic bronchitis with pulmonary hypertension. Br Med $\mathcal{F}$ 1973;iii:467-70.

Department of Health and Social Security. National Health Service England and Wales: amendments to drug tariff. London: DHSS, 1985. (DTA/1Z.)

3 Medical Research Council Working Party. Long term domiciliary oxygen therapy in chronic hypoxaemic cor pulmonale complicating chronic bronchitis and emphysema. Lancet 1981 ; ; $681-5$.

4 Nocturnal Oxygen Therapy Trial Group. Continuous or nocturnal oxygen therapy in hypoxaemic chronic obstructive lung disease: a clinical trial. Ann Intern Med 1980;93:391-8.

5 Biswas CK, Ramos JM, Agroyannis B, Kerr DNS. Blood gas analysis: effect of air bubbles in syringe and delay in estimation. Br Med f 1982;284:923-7.

6 Anonymous. Long-term domiciliary oxygen therapy [Editorial]. Lancet 1985;ii: $365-7$.

(Accepted 16 August 1988)

\section{ANY QUESTIONS}

\begin{abstract}
Is there any evidence that woodworm killers - probably those in use around 10 years ago-cause diseases of the nervous system?
\end{abstract}

In the United Kingdom "woodworm" is usually caused by the wood boring activities of the common furniture beetle (Anobium punctatum). A decade ago infested timber was usually treated with organochlorine compounds such as $\gamma$-hexachlorocyclohexane (lindane). These compounds are highly lipid soluble and will attack the central nervous system. Some are stimulants of the central nervous system, causing hyperexcitability and convulsions, while others have the opposite effect and may cause mental and motor retardation. Although deaths have occurred, these effects are considered to be acute and reversible and there is no evidence of chronic neurological damage.'

Latterly, concern about ecotoxicity and reports of damage to human bone marrow have caused organochlorine compounds to fall from favour. Nowadays pyrethrins (derived from plants such as the chrysanthemum) and the pyrethroid permethrin are the treatments of choice: the latter is probably the most commonly used treatment (personal communication). These compounds are not considered to be neurotoxic. Formulations are usually water based, odourless, and therefore more acceptable to the customer. In the past, however, many preparations were solvent based, often being dissolved in white spirit. It has been alleged, particularly in Scandinavian countries, that long term exposure to this solvent may cause irreversible neurological damage, characterised by premature dementia and peripheral sensorimotor neuropathy. ${ }^{2}$ This so called solvent encephalopathy is a contentious issue. Even if proved, a person would probably need many years of daily exposure to become affected: casual exposure would not be harmful. - ALAN R SCOTT, senior employment medical adviser, Nottingham

1 Clayton GD, Clayton SE, eds. Patty's industrial hygiene and toxicology. Vol 2B. Chichester: J Wiley, 1981:3740-9.

2 Baker EL, Smith TJ. Evaluation of exposure to organic solvents. In: Harrington JM, ed. Recent advances in occupational health 2. London: Churchill Livingstone, 1984:95-9. 